\title{
Glutathione Peroxidase 1
}

National Cancer Institute

\section{Source}

National Cancer Institute. Glutathione Peroxidase 1. NCI Thesaurus. Code C60309.

Glutathione peroxidase 1 (203 aa, 22 kDa) is encoded by the human GPX1 gene. This protein plays a role in glutathione metabolism, peroxide reduction and hemoglobin homeostasis. 